\title{
Influence of soft magnetic material in a permanent magnet synchronous machine with a commercial induction machine stator
}

Isabelle Hofman ${ }^{1,2}$, Peter Sergeant ${ }^{1,2}$, Alex Van den Bossche ${ }^{2}$

Dept. Electrotechnology, University College Ghent, Gent, Belgium

2 Dept. Electrical Energy, Systems \& Automation, Ghent University, Gent, Belgium

\section{Introduction}

The efficiency of a commercial Induction Motor (IM), which is robust and cheap but where efficiency is low at low speed and power, can be optimized by:

Converting the rotor to a synchronous rotor

Replacing the electrical steel in the stator by another material grade To compare the several machines, we use the average and maximal efficiency that are defined in a torque range $0.5 \mathrm{~T}_{\text {nom }}-\mathrm{T}_{\text {nom }}$ and in a speed range $0.5 \Omega_{\text {nom }}-\Omega_{\text {nom }}$.

\section{Methodology}
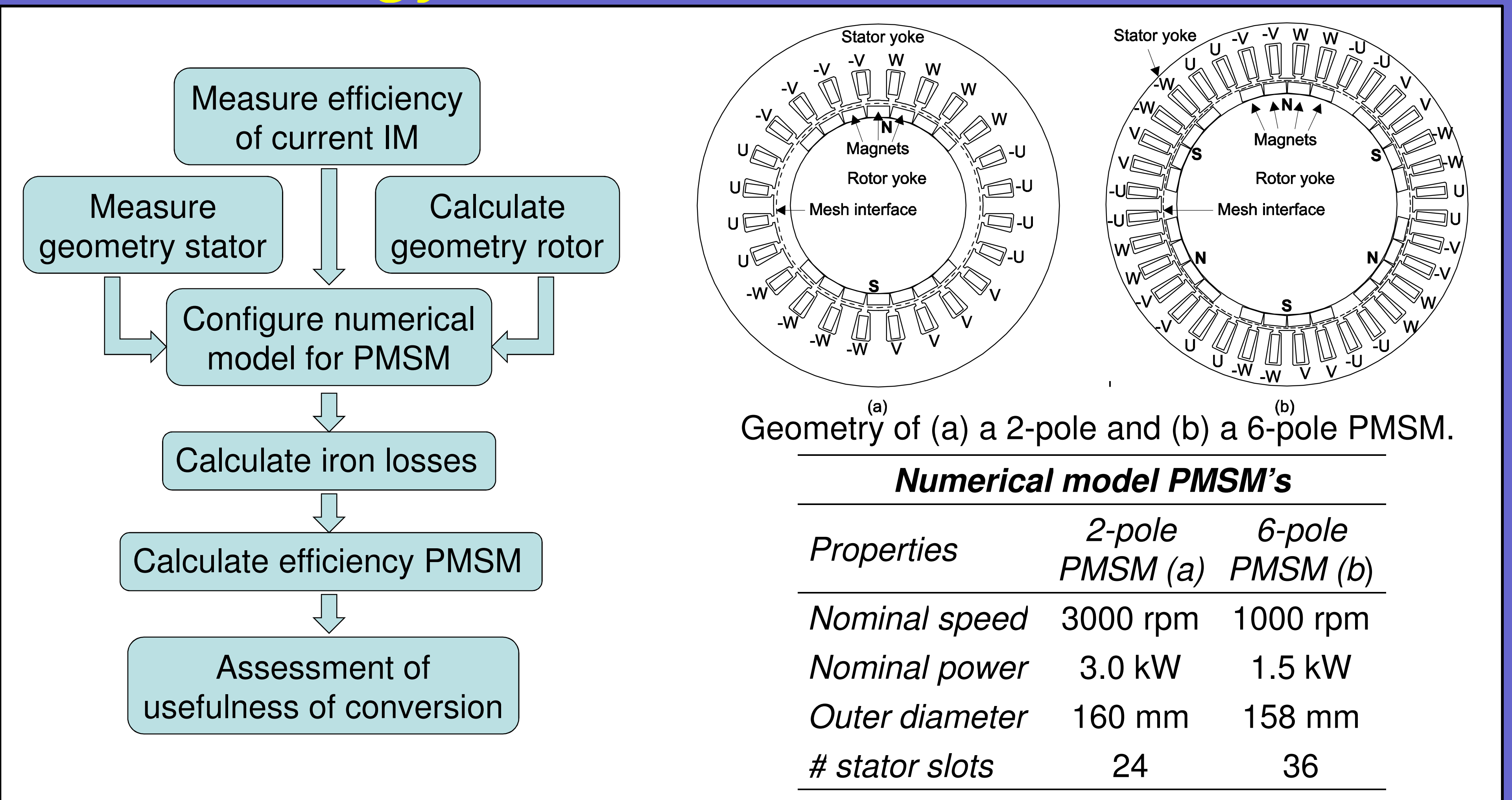

\section{Numerical and loss model}

Two PMSM's were simulated by using a transient 2D Finite Element Model (FEM), taking into account the rotor movement.

A time domain loss model based on the loss separation theory was used to calculate the iron losses.

The loss model parameters were estimated based on loss measurements of the stator. Hysteresis loops could be measured of the material inside the machine in order to identifiy the parameters in the static and dynamic hysteresis model.

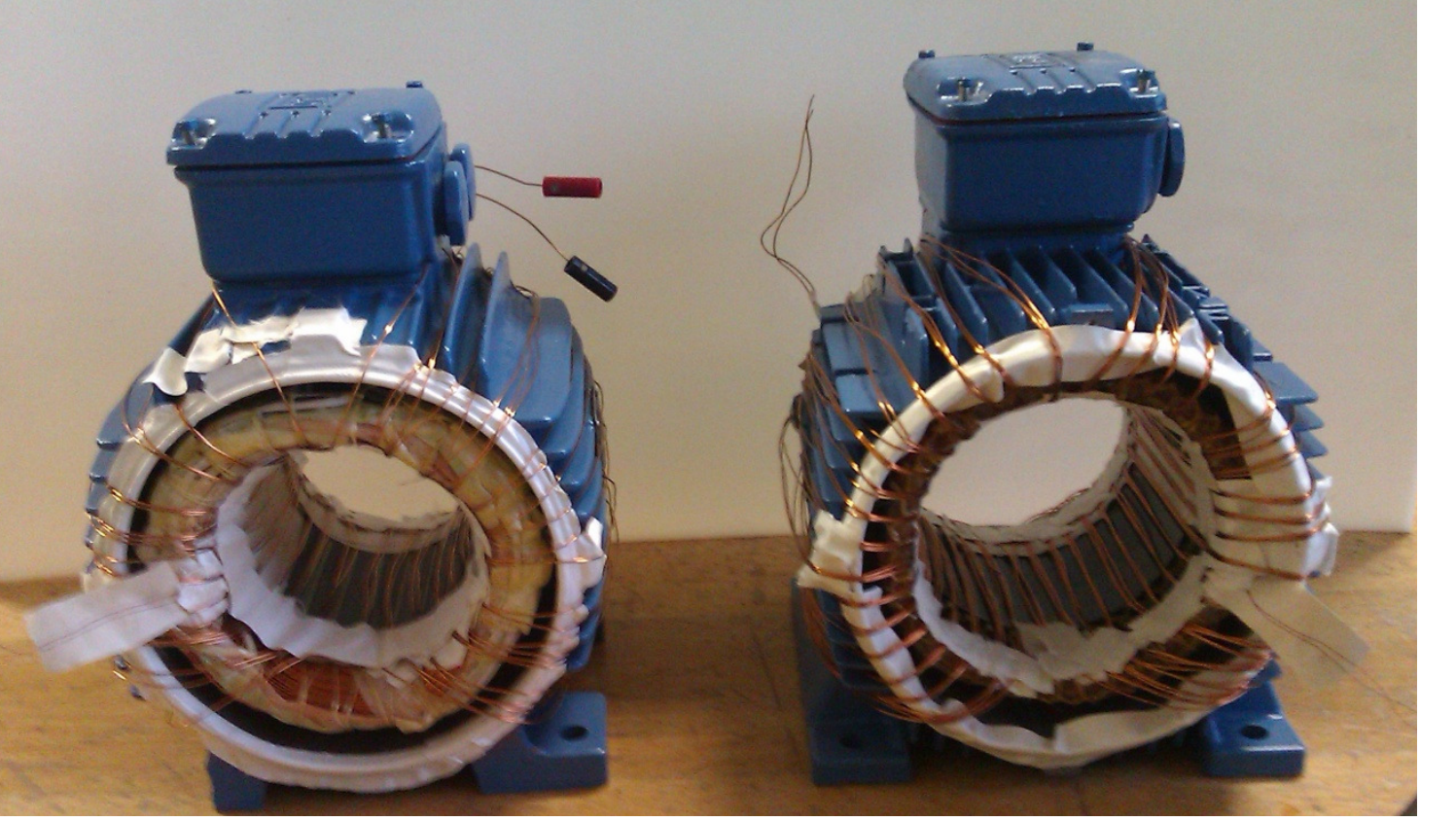

Stator with excitation and measurement winding

The loss parameters were determined by a function based on five material specific coefficients $[a, a, b, c, d]$ that gives the loss in W/kg over a time period of the magnetic induction.

The total average power $P\left(B_{p}, f\right): P\left(B_{p}, f\right)=P_{h y}\left(B_{p}, f\right)+P_{d y}\left(B_{p}, f\right)$

Coefficients $a$ and $\alpha$ are fitted based on hysteresis loop measurements with peak inductions $B_{p}$ between $0.05 \mathrm{~T}$ and $1.8 \mathrm{~T}$ and $0.5 \mathrm{~Hz}$ frequency: $P_{h y}\left(B_{p}, f\right)=a B_{p}^{\alpha} f$

The equation in time domain loss model:

$$
P(B(t))=b\left|\frac{d B(t)}{d t}\right|^{2}+c\left|\frac{d B(t)}{d t}\right|\left(\sqrt{1+d\left|\frac{d B(t)}{d t}\right|}-1\right)+P_{h y}(B(t))
$$

$b, c$ and $d$ are fitting parameters. If the electrical conductivity $\sigma$ is known, $b$ can be found as $b=\frac{\sigma D^{2}}{12}$ with $D$ the sheet thickness.

The losses in the copper stator windings are computed from the enforced stato current and the measured resistance at the steady state temperature of $50^{\circ} \mathrm{C}$.

\section{Experiments}

Two test setup's were made, one for the IM and one for the PMSM, both with the same stator.

Test setup IM:

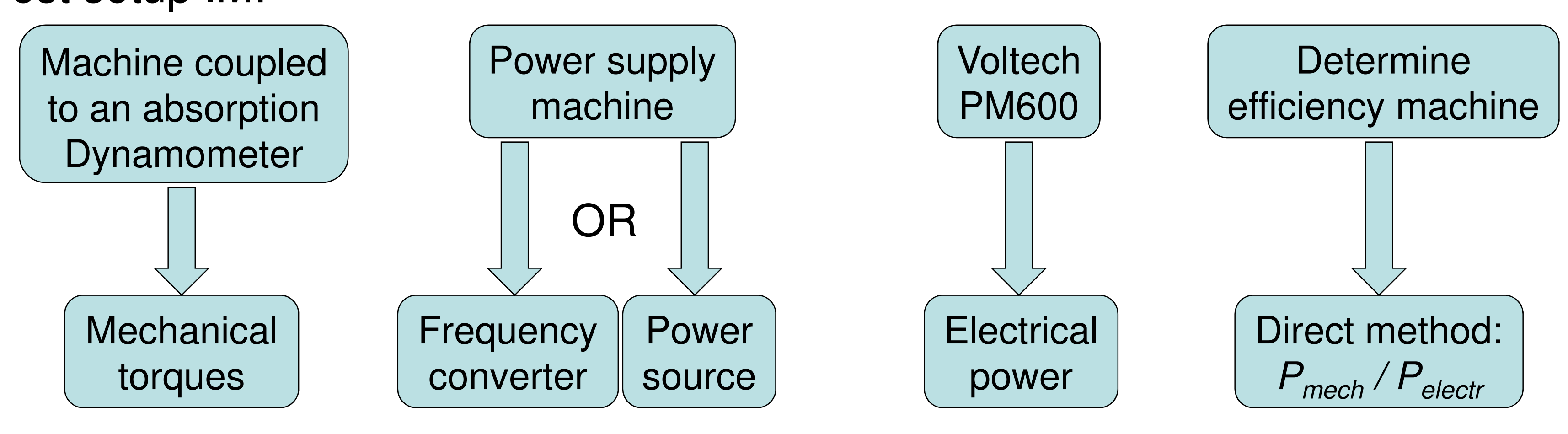

Test setup PMSM:

Rotor reduced in diameter on a lathe and magnets were glued on the surface Permanent NdFeB magnet rotor with unchanged stator.

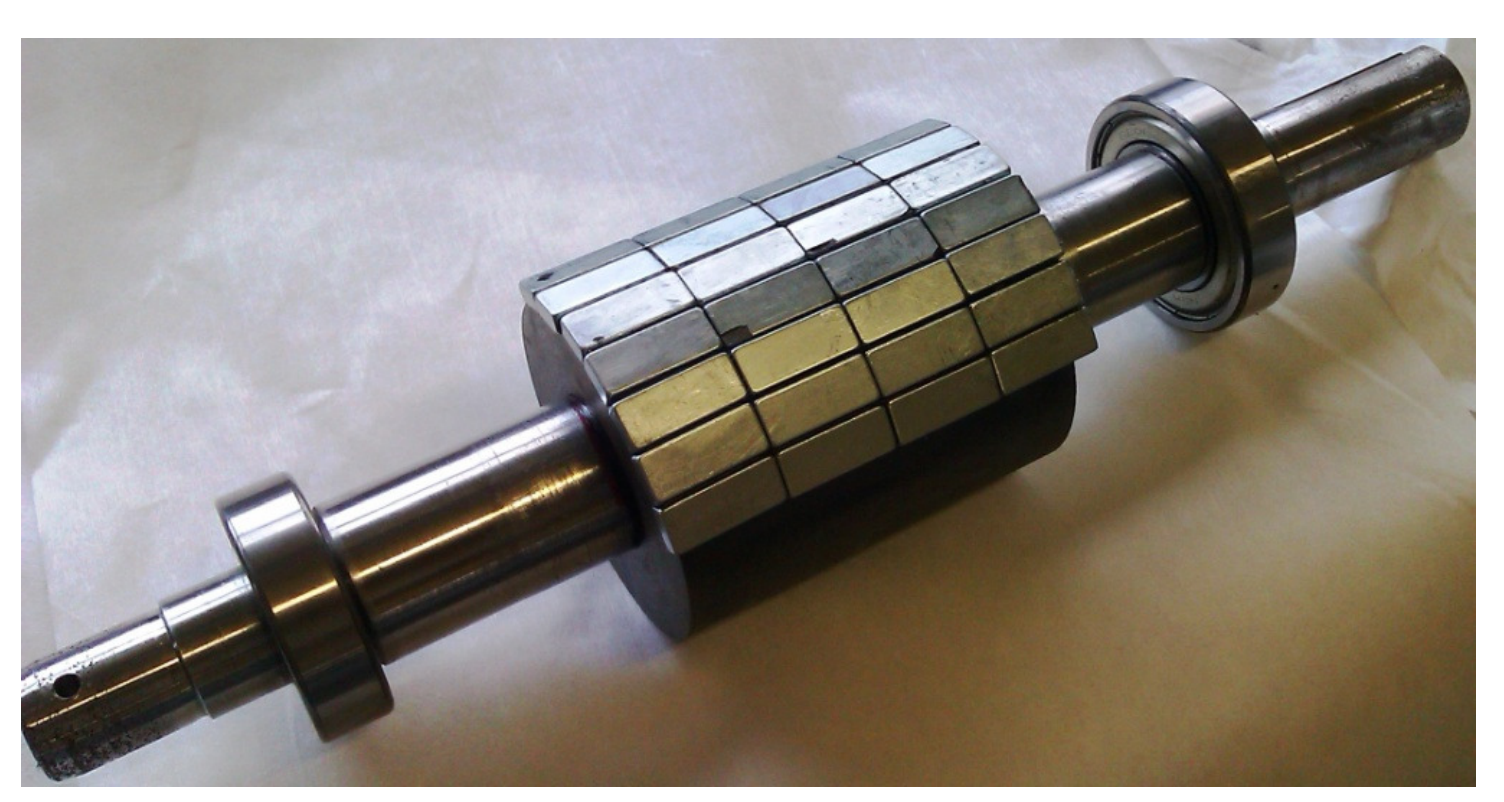

\section{Results}

Measured efficiency maps of a 6-pole IM and the converted 6-pole PMSM:

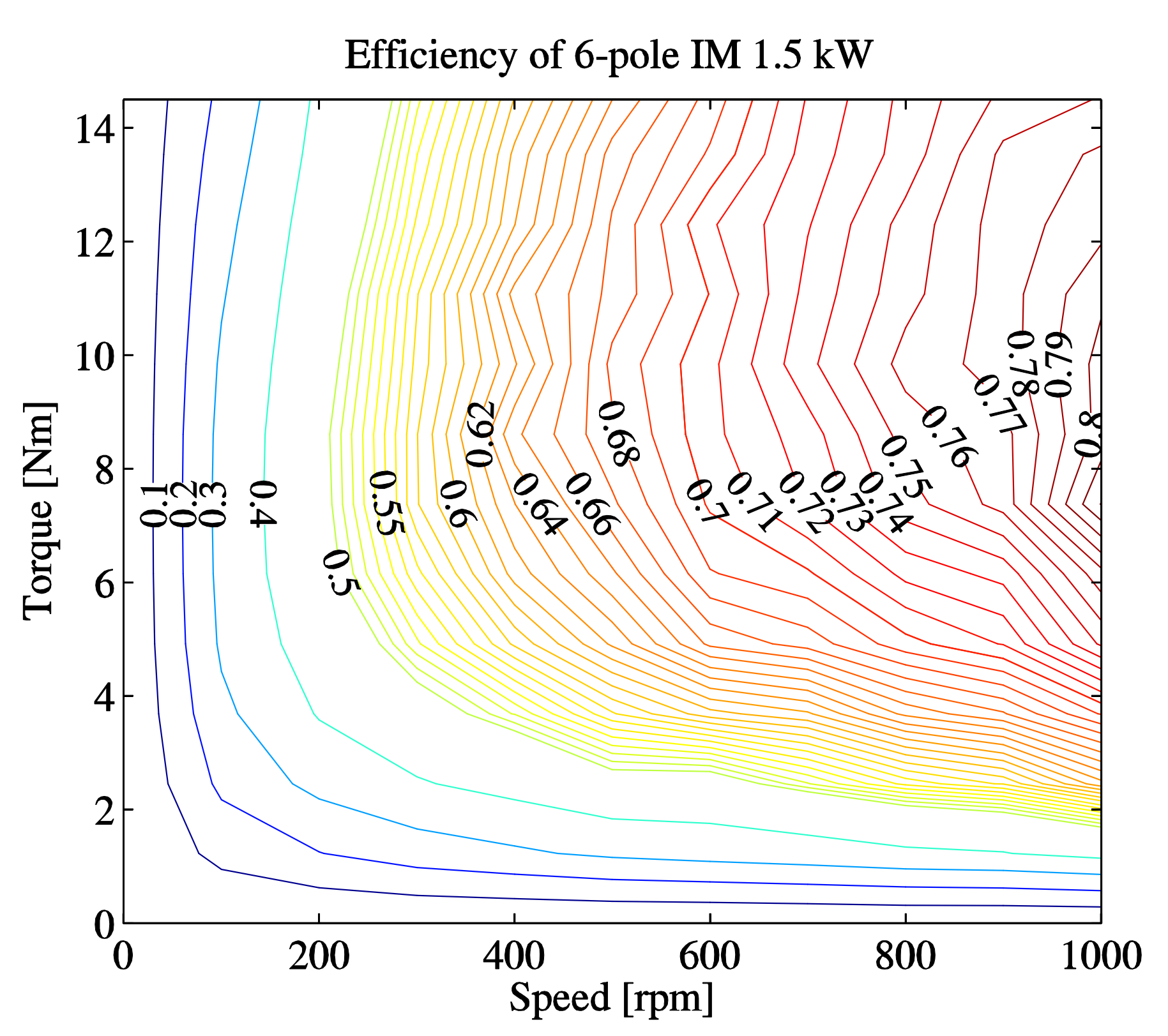

(a)

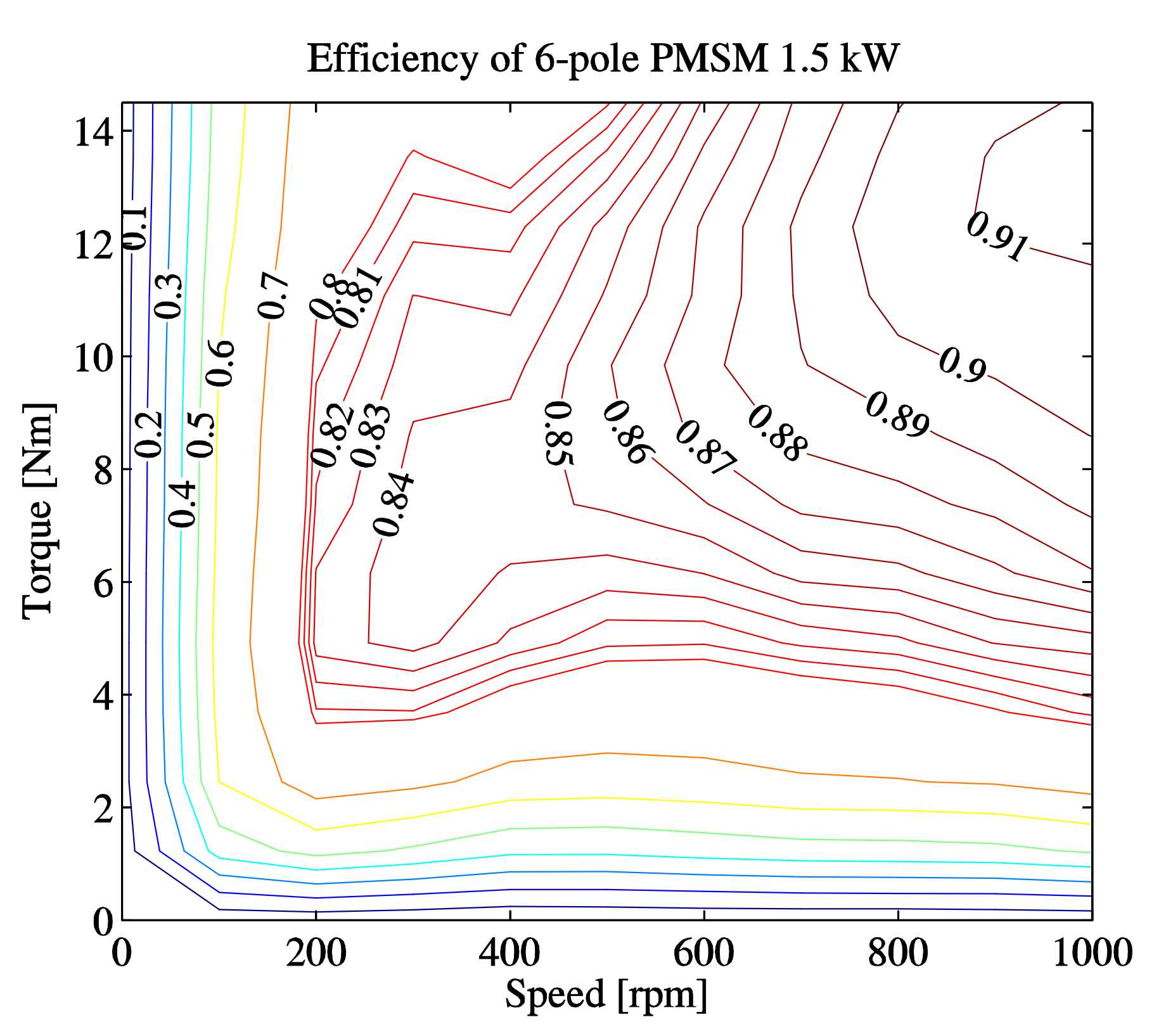

The measured efficiency maps for (a) a 6-pole IM and (b) the converted 6-pole PMSM with original stator iron (M800-50A). Note for clarity of the figure, the contour lines are not equidistan for $\eta<0.8$

For validation of the numerical model we also computed the PMSM's:

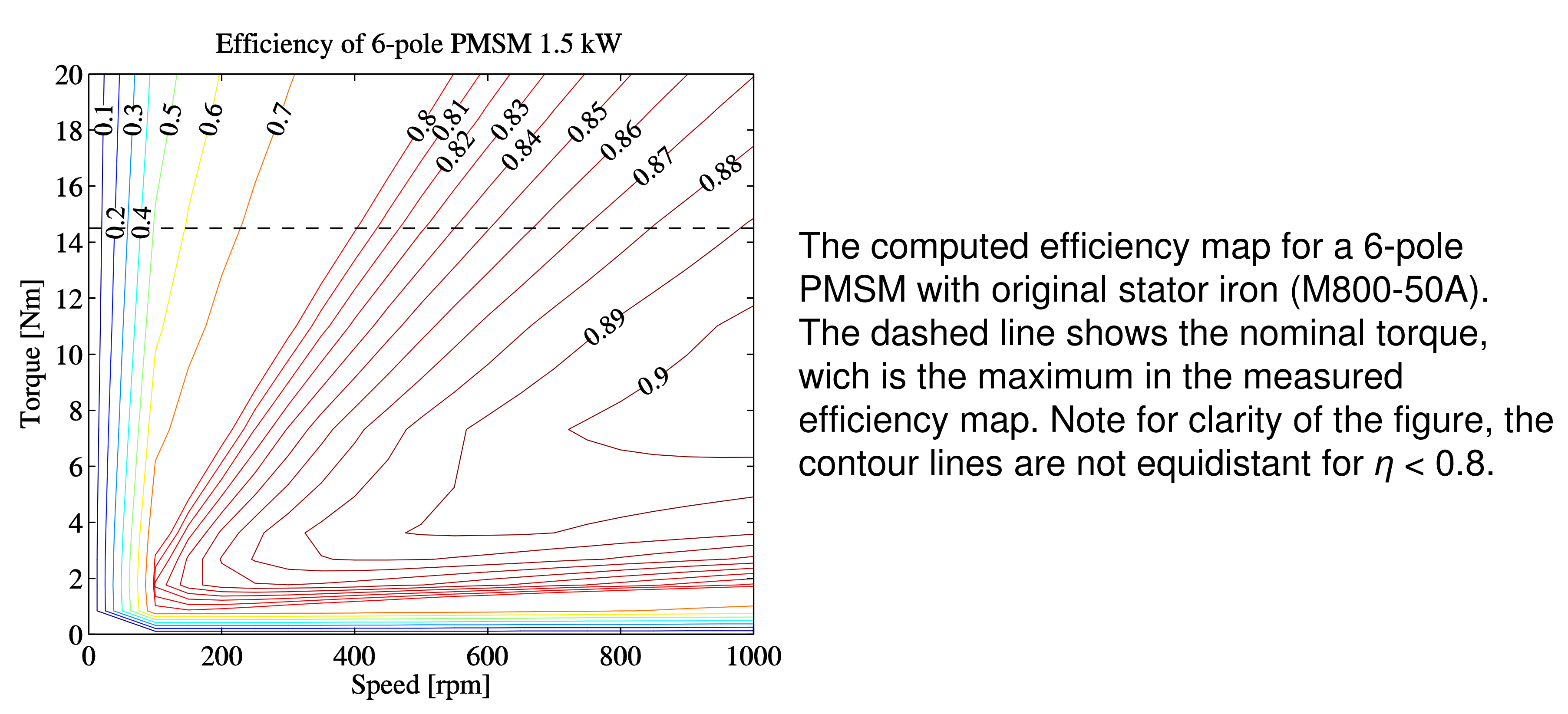

The same was done for another machine, a 2-pole machine.

The efficiency results for a 6-pole and 2-pole machine with original stator steel:

\begin{tabular}{llll}
\hline \multicolumn{3}{c}{$\begin{array}{r}\text { Efficiency of 1.5 kW 6-pole machine } \\
\text { (M800-50A) }\end{array}$} \\
\hline & & $\begin{array}{c}\text { Average } \\
\text { efficiency }\end{array}$ & $\begin{array}{c}\text { Maximum } \\
\text { efficiency }\end{array}$ \\
\hline Measured & IM & $73.53 \%$ & $82.04 \%$ \\
& $P M S M$ & $88.36 \%$ & $92.18 \%$ \\
\hline Computed & $P M S M$ & $88.29 \%$ & $90.70 \%$ \\
\hline
\end{tabular}

\begin{tabular}{llll}
\hline \multicolumn{3}{c}{$\begin{array}{c}\text { Efficiency of 3.0 kW 2-pole machine } \\
\text { (M800-50A) }\end{array}$} \\
\hline & & $\begin{array}{c}\text { Average } \\
\text { efficiency }\end{array}$ & $\begin{array}{c}\text { Maximum } \\
\text { efficiency }\end{array}$ \\
\hline Measured & $I M$ & $83.24 \%$ & $86.27 \%$ \\
& $P M S M$ & $85.47 \%$ & $89.72 \%$ \\
\hline Computed & $P M S M$ & $92.08 \%$ & $93.70 \%$ \\
\hline
\end{tabular}

In a second study the FEM of the 6-pole and 2-pole PMSM are simulated for different kinds of magnetic materials in the stator. The influence on the efficiency of magnetic materials such as M235-35A, M250-50A, M330-50A, M330p-50A and M600-50A was investigated. The loss parameters for each material were added to the loss model.

\section{Efficiency of $1.5 \mathrm{~kW}$ 6-pole computed PMSM}

\section{Iron stator Average Maximum} Soft magnetic material efficiency efficiency M235-35A

M250-50A

M330-50A

M330p-50A

M600-50A

M800-50A (original) $90.15 \% \quad 94.10 \%$ $90.16 \% \quad 94.04 \%$ $90.00 \% \quad 93.86 \%$ $89.82 \% \quad 93.43 \%$

\begin{tabular}{lcc}
\hline \multicolumn{3}{l}{ Efficiency of 3.0 kW 2-pole computed PMSM } \\
\hline Iron stator & $\begin{array}{c}\text { Average } \\
\text { Sofficiency }\end{array}$ & $\begin{array}{c}\text { Maximum } \\
\text { efficiency }\end{array}$ \\
\hline Soft magnetic material & $93.65 \%$ & $96.54 \%$ \\
M255-35A & $93.64 \%$ & $96.47 \%$ \\
M330-50A & $93.51 \%$ & $96.29 \%$ \\
M330p-50A & $93.31 \%$ & $95.90 \%$ \\
M600-50A & $92.92 \%$ & $95.30 \%$ \\
M800-50A (original) & $92.08 \%$ & $93.70 \%$ \\
\hline
\end{tabular}

The M235-35A magnetic material had the highest peak efficiency for both PMSM's

\section{Conclusions}

Small IM's with many poles, in this case 6-poles, are not efficient unless the IM is converted into a PMSM where the efficiency increases a lot. 